\title{
RANCANG BANGUN TURBIN ANGIN SUDU FLAT POROS \\ HORIZONTAL DENGAN VARIASI PERBANDINGAN LUAS CELAH AIR EXIT GUNA MENINGKATKAN KINERJA PLTB
}

\author{
Anang Setya Darmawan, Dila Pratiwi, Iqsal Elviyansa, Muhammad Ilham Nazzahudin , Bono, \\ Suwarti \\ Program Studi Teknik Konversi Energi \\ Jurusan Teknik Mesin Politeknik Negeri Semarang \\ J1. Prof H. Sudarto, SH., Tembalang, Kotak Pos 6199/SMS, Semarang 50329 \\ Telp. 7473417, 7499585 (Hunting), Fax. 7472396
}

\begin{abstract}
Abstrak
Tujuan utama dari penelitian ini adalah mengembangkan desain turbin angin sudu flat dengan penambahan penyempitan celah (air exit split) di sepanjang keluaran sudu turbin angin dengan memberikan variasi perbandingan luas celah antara luas celah udara masuk dan luas celah udara keluar pada air exit berfungsi untuk memberikan tambahan gaya dorong saat sudu turbin angin berputar sehingga meningkatkan efisiensi turbin. Hal yang melatar belakangi pembuatan turbin ini yaitu untuk membuat turbin dengan efisiensi yang lebih besar dengan skala pembuatan turbin sesuai dengan parameter yang digunakan di laboratorium sehingga kedepannya dapat dikembangkan menjadi turbin angiin yang dapat dimanfaatkan dalam kehidupan nyata. Turbin angin yang digunakan dalam rancang bangun ini menggunakan bahan dasar plat galvanis dengan tebal plat 1 mm yang dibentuk sedemikian rupa yang memiliki lebar sudu $8 \mathrm{~cm}$ dan $10 \mathrm{~cm}$ serta variasi lebar celah masuk air exit sebesar $40 \mathrm{~mm}, 34 \mathrm{~mm}, 32 \mathrm{~mm}$ dan $30 \mathrm{~mm}$. Pengujian turbin angin ini menggunakan variabel berupa kecepatan angin $6 \mathrm{~m} / \mathrm{s}, 7 \mathrm{~m} / \mathrm{s}, 8 \mathrm{~m} / \mathrm{s}, 9 \mathrm{~m} / \mathrm{s}$ dan $10 \mathrm{~m} / \mathrm{s}$. metode pengujian alat dilakukan di laboratorium dengan bantuan blower sebagai penghembus angina. sedangkan parameter uji berupa putaran poros turbin, putaran poros generator, torsi generator, tegangan, dan arus. Data-data hasil pengujian berupa tegangan generator,arus yang dihasilkan generator, torsi pada generator dan putaran pada generator selanjutnya diolah untuk mengetahui efisiensi sistem dan daya output. Data tersebut diolah dan didapatkan efisiensi terbaik pada sudu flat lebar sudu $80 \mathrm{~mm}$ yaitu sebesar $6.01 \%$ untuk putaran $184.2 \mathrm{rpm}$ pada kecepatan angina $6 \mathrm{~m} / \mathrm{s}$ dengan penambahan air exit variasi lebar celah masuk $40 \mathrm{~mm}$. Efisiensi terbaik pada sudu flat lebar sudu 100 mm yaitu sebesar 3.29\% untuk putaran $176.3 \mathrm{rpm}$ pada kecepatan angina $6 \mathrm{~m} / \mathrm{s}$ dengan penambahan air exit variasi lebar celah masuk $40 \mathrm{~mm}$.
\end{abstract}

Kata kunci : Turbin Angin Poros Horizontal Sudu Flat Air Exit Split, lebar celah masuk, gaya doromg

\section{Pendahuluan}

Angin merupakan sumber daya yang tidak ada habisnya. Di Indonesia terdapat beberapa daerah yang memiliki potensi energi angin unuk produksi listrik. Energi angin dapat dimanfaatkan untuk produksi listrik dan mendukung program pengurangan emisi karena tidak menghasilkan emisi $\mathrm{CO} 2$ selama proses produksi energi listrik oleh turbin angin.

Turbin angin yang banyak digunakan saat ini adalah poros horizontal (TAPH). Jenis turbin angin poros horizontal yang memiliki unjuk kerja yang lebih baik adalah rotor sudut tipe propeller. Jenis rotor propeller dengan sudu multi blade bekerja optimum pada kecepatan angin yang relatif rendah. Kelebihan dari turbin angin poros horizontal (TAPH) adalah memiliki efisiensi yang lebih tinggi, karena sudu selalu bergerak tegak lurus terhadap angin dan menerima daya sepanjang putaran. Pemanfaatannya yang umum sekarang sudah digunakan adalah untuk memompa air dan pembangkit listrik tenaga angin. Pembangkit listrik tenaga angin yang berkembang saat ini masih memiliki daya yang relatif kecil, hal tersebut dikarenakan turbin yang ada masih memiliki efisiensi yang rendah. Oleh 
karena itu, pada penelitian ini sudu turbin propeller yang semula dengan sudu flat akan dikembangkan dengan menambahkan variasi lebar celah air exit. Dengan adanya variasi tersebut diharapkan gaya dorong yang didapatkan tinggi sehingga dapat meningkatkan kinerja turbin.Dari data Badan meteorologi, Klimatologi dan Geofisika (BMKG) menyatakan bahwa kecepatan angin di tiap daerah di Indonesia berbeda-beda, pada tahun 2015 kecepatan angin tertinggi terjadi di daerah Kepulauan Bangka Belitung sebesar 4,05 m/s, daerah Nusa Tenggara Timur sebesar 4,04 m/s, dan daerah Jawa Timur sebesar $3,88 \mathrm{~m} / \mathrm{s}$. Dari data kecepatan angin tersebut menunjukkan bahwa kecepatan angin di Indonesia cenderung memiliki kecepatan angin yang rendah, oleh karena itu muncul gagasan untuk membuat turbin angin dengan kecepatan angin relatif rendah yaitu turbin angin sudu flat tipe poros horizontal. Penelitian ini adalah melanjutkan dari penelitian sebelumnya, mengenai kinerja turbin angin dengan penambahan sudu air exit split pada tipe poros horizontal dengan variasi sudut air exit sebesar $30^{\circ}, 45^{\circ}$, dan $60^{\circ}$ oleh Tri Mulyo, dkk. Dari penelitian tersebut diperoleh hasil bahwa turbin yang menghasilkan efisiensi paling baik adalah sudut air exit sebesar $60^{\circ}$. Dari hasil penelitian tersebut muncul sebuah gagasan untuk membuat variasi lebar celah pada sisi bagian masuk air exit masing masing $30 \mathrm{~mm}$, $32 \mathrm{~mm}, 34 \mathrm{~mm}$, dan $40 \mathrm{~mm}$. dengan harapan mampu meningkatkan nilai efisiensi turbin angin menjadi lebih baik. Turbin angin sudu flat poros horizontal dengan variasi lebar celah air exit merupakan turbin angin poros horizontal pengembangan dari turbin angin sudu flat poros horizontal dengan penambahan sudu air exit. Turbin angin sudu flat poros horizontal dengan penambahan sudu air exit split yang sudah ada memiliki sudut terbaik $60^{\circ}$, sehingga dilakukan penelitian kembali untuk mendapatkan lebar celah masuk air exit yang memiliki efisiensi tertinggi. angin sudu flat poros horizontal variasi lebar celah air exit cocok untuk kecepatan angin yang relatif rendah sekitar 6-8 $\mathrm{m} / \mathrm{s}$. Dalam penelitian ini, digunakan dua perumusan masalah yaitu pengembangan turbin angin sudu flat poros horizontal dengan variasi lebar celah air exit yaitu :

a. Apakah pemberian variasi perbandingan lebar celah air exit pada sudu turbin angin propeller dengan sudu flat dapat menghasilkan daya mekanik yang besar sehingga menghasilkan efisiensi yang tinggi?

b. Apakah pemberian variasi perbandingan lebar celah air exit pada sepanjang keeluaran sudu memberikan pengaruh pada kecepatan keluaran sudu? Untuk menjawab perumusan masalah tersebut maka akan dilakukan variasi lebar celah $30 \mathrm{~mm}, 32 \mathrm{~mm}, 34 \mathrm{~mm}$ dan $40 \mathrm{~mm}$

\section{Metode Penelitian}

Dalam penelitian ini metode yang digunakan adalah dengan melakukan penelusuran sumber-sumber pustaka yang terkait dengan penelitian kami, serta dengan cara melakukan pengujian terhadap turbin yang kami buat. Untuk mendapatkan pemahaman yang komprehensif, langkah-langkah penelitian diuraikan seperti berikut ini. Persiapan langkah ini dilakukan berdasarkan objek penelitian meliputi jurnal-jurnal dan artikel. Metode ini dilakukan dengan cara menelusuri di internet dan mempelajari buku-buku tentang turbin angin yang telah ada dari perpustakaan. Desain model turbin,setelah melakukan studi pustaka didapatkan beberapa sumber pustaka tentang model turbin.Turbin angin sudu flat poros horizontal dengan penambahan sudu air exit yang telah ada terbuat dari bahan plat galvanis 
ketebalan 1,2 mm. Kemudian untuk pembuatan variasi lebar sudu dan variasi lebar celah air exit dibuat dari bahan yang sama, yaitu plat galvanis dengan ketebalan $1 \mathrm{~mm}$. Sudu flat mempunyai panjang $30 \mathrm{~cm}$ dan lebar sudu $8 \mathrm{~cm}$ dan $10 \mathrm{~cm}$. sudu air exit mempunyai panjang dan lebar $6 \mathrm{~cm}$. Pada penelitian ini akan dibuat model turbin angin sudu flat poros horizontal dengan variasi lebar celah masuk $30 \mathrm{~mm}, 32 \mathrm{~mm}, 34 \mathrm{~mm}$, dan 40 mm. Teknik pengumpulan data didapatkan dengan menggunakan1 set blower untuk memutar turbin angin, anemometer untuk mengetahui kecepatan angin , neraca pegas (dynamometer) untuk mengukur massa untuk mendapatkan nilai torsi, tachometer untuk mengukur kecepatan putaran poros turbin angin, tegangan dengan menggunakan voltmeter dan arus dengan menggunakan amperemeter. Uji kinerja turbin, dilakukan untuk mengetahui kinerja dari variasi celah $30 \mathrm{~mm}, 32 \mathrm{~mm}, 34 \mathrm{~mm}$, dan $40 \mathrm{~mm}$ kemudian dari pengujian tersebut diperoleh lebar celah masuk air exit terbaik .Pengujian dilakukan pada 5 variasi kecepatan angin, yaitu $6 \mathrm{~m} / \mathrm{s}, 7$ $\mathrm{m} / \mathrm{s}, 8 \mathrm{~m} / \mathrm{s}, 9 \mathrm{~m} / \mathrm{s}$ dan $10 \mathrm{~m} / \mathrm{s}$. Parameter yang diukur dalam pengujian adalah massa untuk mendapatkan nilai torsi, putaran turbin, kecepatan angin, tegangan dan arus. Setelah semua pengujian selesai maka didapat data hasil kinerja dari turbin dan selanjutnya dapat dibuat grafik karakteristik kinerja dari turbin tersebut. Melakukan pengolahan data ditunjukan dalam bentuk tabel dan kurva karakteristik kinerja turbin angin.

\section{Hasil dan Pembahasan}

Model turbin yang kami gunakan untuk penelitian ini adalah seperti gambar 1 dibawah ini.

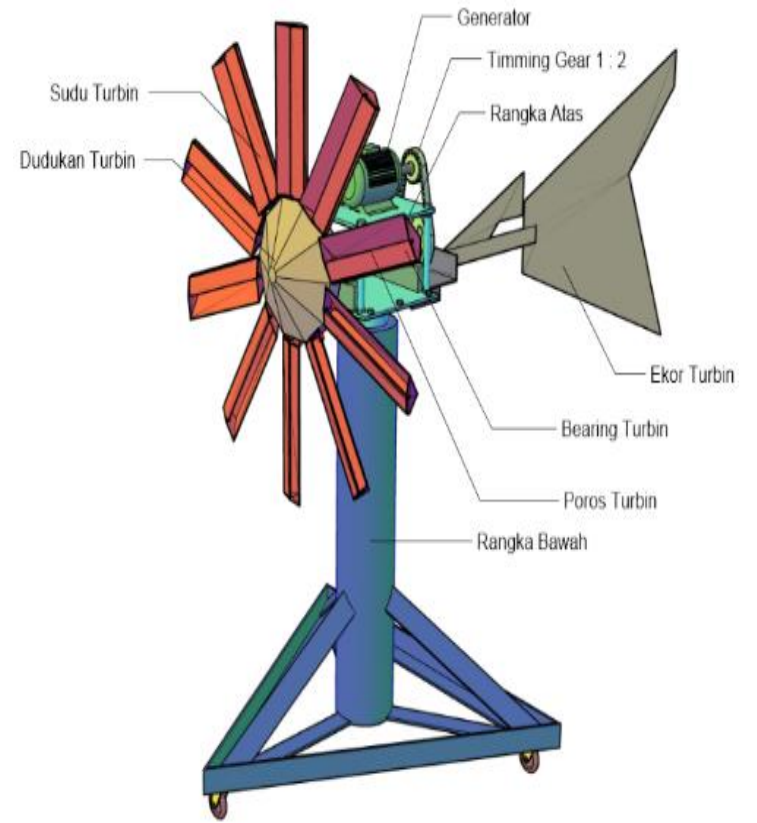

\section{Gambar 1.Model Turbin Angin}

Sudu Flat Poros Horizontal dengan

Variasi Lebar Celah Masuk Air Exit

Berikut adalah data hasil percobaan dan pengolahan data kami sajikan dalam bentuk tabel dan grafik.

Tabel 1 Hasil Pengujian Lebar Celah 30 $\mathrm{mm}$ pada kecepatan angin $6 \mathrm{~m} / \mathrm{s}$

\begin{tabular}{|c|c|c|c|c|c|c|c|c|}
\hline No & $\begin{array}{c}\text { Kecepatan } \\
\text { angin (m/s) }\end{array}$ & $\begin{array}{c}\text { Beban } \\
\text { (Watt) }\end{array}$ & $\begin{array}{c}\text { Tegangan } \\
(\mathbf{V})\end{array}$ & Arus (A) & $\begin{array}{c}\text { Putaran } \\
\text { Generator (rpm) })\end{array}$ & $\begin{array}{c}\text { Putaran } \\
\text { Turbin }(\mathrm{rpm})\end{array}$ & Torsi (Kg) & $\begin{array}{c}\text { Luas } \\
\text { Sapuan (m) }\end{array}$ \\
\hline 1 & 6 & 0 & 18.0 & 0.00 & 214.9 & 107.45 & 0 & 0.608 \\
\hline 2 & 6 & 5 & 12.5 & 0.30 & 207.4 & 103.70 & 0.152 & 0.608 \\
\hline 3 & 6 & 10 & 8.0 & 0.48 & 198.4 & 99.20 & 0.250 & 0.608 \\
\hline 4 & 6 & 15 & 6.2 & 0.64 & 189.3 & 94.65 & 0.295 & 0.608 \\
\hline 5 & 6 & 20 & 4.8 & 0.76 & 164.7 & 82.35 & 0.305 & 0.608 \\
\hline 6 & 6 & 25 & 4.0 & 0.82 & 152.5 & 76.25 & 0.330 & 0.608 \\
\hline 7 & 6 & 30 & 3.8 & 0.83 & 140.1 & 70.05 & 0.350 & 0.608 \\
\hline 8 & 6 & 35 & 3.2 & 0.88 & 138.2 & 69.10 & 0.370 & 0.608 \\
\hline 9 & 6 & 40 & 2.6 & 0.97 & 134.9 & 67.45 & 0.390 & 0.608 \\
\hline 10 & 6 & 45 & 2.3 & 0.97 & 127.4 & 63.70 & 0.410 & 0.608 \\
\hline 11 & 6 & 50 & 2.0 & 0.90 & 119.8 & 59.90 & 0.415 & 0.608 \\
\hline 12 & 6 & 60 & 2.0 & 0.92 & 116.2 & 58.10 & 0.425 & 0.608 \\
\hline 13 & 6 & 70 & 1.7 & 0.93 & 109.3 & 54.65 & 0.435 & 0.608 \\
\hline 14 & 6 & 80 & 1.7 & 0.95 & 107.9 & 53.95 & 0.440 & 0.608 \\
\hline 15 & 6 & 90 & 1.7 & 0.96 & 102.2 & 51.10 & 0.475 & 0.608 \\
\hline 16 & 6 & 100 & 1.6 & 0.96 & 98.1 & 49.05 & 0.470 & 0.608 \\
\hline 17 & 6 & 110 & 1.6 & 0.98 & 96.2 & 48.10 & 0.495 & 0.608 \\
\hline 18 & 6 & 120 & 0.8 & 1.00 & 92.1 & 46.05 & 0.500 & 0.608 \\
\hline 19 & 6 & 130 & 0.8 & 1.10 & 86.9 & 43.45 & 0.510 & 0.608 \\
\hline 20 & 6 & 140 & 0.8 & 1.20 & 80.1 & 40.05 & 0.520 & 0.608 \\
\hline
\end{tabular}

Tabel 2 Hasil Pengujian Lebar Celah 32 $\mathrm{mm}$ pada kecepatan angin $6 \mathrm{~m} / \mathrm{s}$ 


\begin{tabular}{|c|c|c|c|c|c|c|c|c|}
\hline No & $\begin{array}{r}\text { Kecepatan } \\
\text { angin }(\mathrm{m} / \mathrm{s})\end{array}$ & $\begin{array}{l}\text { Beban } \\
\text { (Watt) }\end{array}$ & $\begin{array}{c}\text { Tegangan } \\
\text { (V) }\end{array}$ & Arus (A) & \begin{tabular}{c|} 
Putaran \\
Generator $(\mathrm{rpm})$
\end{tabular} & \begin{tabular}{|c|c} 
Putaran \\
Turbin (rpm) \\
\end{tabular} & Torsi (Kg) & $\begin{array}{c}\text { Luas } \\
\text { Sapuan }(\mathrm{m})\end{array}$ \\
\hline 1 & 6 & 0 & 18.0 & 0.00 & 220.3 & 110.15 & 0 & 0.608 \\
\hline 2 & 6 & 5 & 13.0 & 0.34 & 208.9 & 104.45 & 0.152 & 0.608 \\
\hline 3 & 6 & 10 & 8.0 & 0.52 & 193.4 & 96.70 & 0.250 & 0.608 \\
\hline 4 & 6 & 15 & 6.2 & 0.64 & 189.2 & 94.60 & 0.295 & 0.608 \\
\hline 5 & 6 & 20 & 4.5 & 0.71 & 167.7 & 83.85 & 0.305 & 0.608 \\
\hline 6 & 6 & 25 & 4.0 & 0.80 & 157.5 & 78.75 & 0.330 & 0.608 \\
\hline 7 & 6 & 30 & 3.8 & 0.86 & 142.2 & 71.10 & 0.350 & 0.608 \\
\hline 8 & 6 & 35 & 3.0 & 0.90 & 139.1 & 69.55 & 0.370 & 0.608 \\
\hline 9 & 6 & 40 & 2.1 & 0.97 & 135.2 & 67.60 & 0.390 & 0.608 \\
\hline 10 & 6 & 45 & 2.1 & 0.98 & 129.4 & 64.70 & 0.410 & 0.608 \\
\hline 11 & 6 & 50 & 1.8 & 0.90 & 120.8 & 60.40 & 0.415 & 0.608 \\
\hline 12 & 6 & 60 & 1.8 & 0.92 & 118.9 & 59.45 & 0.425 & 0.608 \\
\hline 13 & 6 & 70 & 1.7 & 0.93 & 116.7 & 58.35 & 0.435 & 0.608 \\
\hline 14 & 6 & 80 & 1.7 & 0.95 & 111.3 & 55.65 & 0.440 & 0.608 \\
\hline 15 & 6 & 90 & 1.7 & 0.96 & 110.9 & 55.45 & 0.475 & 0.608 \\
\hline 16 & 6 & 100 & 1.6 & 0.96 & 109.8 & 54.90 & 0.470 & 0.608 \\
\hline 17 & 6 & 110 & 1.6 & 0.98 & 98.2 & 49.10 & 0.495 & 0.608 \\
\hline 18 & 6 & 120 & 0.8 & 1.00 & 96.3 & 48.15 & 0.500 & 0.608 \\
\hline 19 & 6 & 130 & 0.8 & 1.10 & 96.9 & 48.45 & 0.510 & 0.608 \\
\hline 20 & 6 & 140 & 0.8 & 1.20 & 80.2 & 40.10 & 0.520 & 0.608 \\
\hline
\end{tabular}

Tabel 3 Hasil Pengujian Lebar Celah 34 $\mathrm{mm}$ pada kecepatan angin $6 \mathrm{~m} / \mathrm{s}$

\begin{tabular}{|c|c|c|c|c|c|c|c|c|}
\hline No & $\begin{array}{l}\text { Kecepatan } \\
\text { angin }(\mathrm{m} / \mathrm{s})\end{array}$ & $\begin{array}{l}\text { Beban } \\
\text { (Watt) }\end{array}$ & \begin{tabular}{|c|} 
Tegangan \\
(V)
\end{tabular} & Arus (A) & \begin{tabular}{c|} 
Putaran \\
Generator $(\mathrm{rpm})$
\end{tabular} & $\begin{array}{c}\text { Putaran } \\
\text { Turbin (rpm) }\end{array}$ & Torsi (N) & $\begin{array}{c}\text { Luas } \\
\text { Sapuan }(\mathrm{m})\end{array}$ \\
\hline 1 & 6 & 0 & 13.6 & 0.00 & 239.8 & 119.90 & 0.090 & 0.608 \\
\hline 2 & 6 & 5 & 10.0 & 0.19 & 203.2 & 101.60 & 0.115 & 0.608 \\
\hline 3 & 6 & 10 & 7.0 & 0.37 & 183.4 & 91.70 & 0.220 & 0.608 \\
\hline 4 & 6 & 15 & 4.4 & 0.45 & 154.5 & 77.25 & 0.260 & 0.608 \\
\hline 5 & 6 & 20 & 3.4 & 0.49 & 139.1 & 69.55 & 0.275 & 0.608 \\
\hline 6 & 6 & 25 & 3.0 & 0.55 & 132.4 & 66.20 & 0.325 & 0.608 \\
\hline 7 & 6 & 30 & 2.1 & 0.58 & 127.4 & 63.70 & 0.335 & 0.608 \\
\hline 8 & 6 & 35 & 2.0 & 0.62 & 126.6 & 63.30 & 0.350 & 0.608 \\
\hline 9 & 6 & 40 & 1.9 & 0.67 & 123.1 & 61.55 & 0.375 & 0.608 \\
\hline 10 & 6 & 45 & 1.7 & 0.69 & 120.6 & 60.30 & 0.380 & 0.608 \\
\hline 11 & 6 & 50 & 1.8 & 0.73 & 120.5 & 60.25 & 0.390 & 0.608 \\
\hline 12 & 6 & 60 & 1.6 & 0.77 & 130.9 & 65.45 & 0.400 & 0.608 \\
\hline 13 & 6 & 70 & 1.3 & 0.81 & 127.5 & 63.75 & 0.415 & 0.608 \\
\hline 14 & 6 & 80 & 1.2 & 0.84 & 126.6 & 63.30 & 0.455 & 0.608 \\
\hline 15 & 6 & 90 & 1.1 & 0.86 & 124.1 & 62.05 & 0.460 & 0.608 \\
\hline 16 & 6 & 100 & 0.8 & 0.82 & 121.1 & 60.55 & 0.470 & 0.608 \\
\hline 17 & 6 & 110 & 0.8 & 0.90 & 120.8 & 60.40 & 0.480 & 0.608 \\
\hline 18 & 6 & 120 & 0.7 & 0.82 & 120.7 & 60.35 & 0.475 & 0.608 \\
\hline 19 & 6 & 130 & 0.9 & 0.84 & 119.8 & 59.90 & 0.465 & 0.608 \\
\hline 20 & 6 & 140 & 0.8 & 0.78 & 122.7 & 61.35 & 0.475 & 0.608 \\
\hline
\end{tabular}

Cara Perhitungan

1. Daya Input/Daya kinetic (Pkin)

$v^{3}$

$$
\text { Pkin } \quad=0.5 \times \rho \text { udara } \times \mathrm{A} \mathrm{x}
$$

$$
\begin{aligned}
& =0.5 \times 1.1 \times 0.608 \times 6^{3} \\
& =72.234 \text { watt }
\end{aligned}
$$

2. Daya Output (Poutput) generator Poutput = V x I

$$
=10 \times 0.4
$$

$$
=4 \text { watt }
$$

3. Effisensi Sistem ( $\eta$ Sistem)

$$
\begin{aligned}
\eta \text { Sistem }=\frac{\text { Daya Output Sistem }}{\text { Daya Input Sistem }} \times 100 \% \\
=\frac{4}{72.234} \times 100 \\
=5.53 \%
\end{aligned}
$$

4. Daya Poros (Ps)

$$
\begin{aligned}
\mathrm{PS}= & \frac{2 x \pi x n g x T}{60} \\
& =\frac{2 x \pi x 227,7 x 0,23}{60} \\
& =5.481 \mathrm{Watt}
\end{aligned}
$$

5. Effisiensi Generator

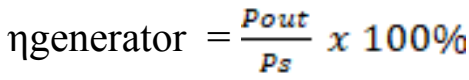

$$
\begin{aligned}
& =\frac{4}{5,481} \times 100 \% \\
& =72,973 \%
\end{aligned}
$$

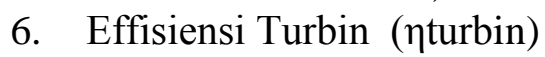

$\eta$ turbin $=\frac{\text { Daya Poros }}{\text { Daya Input }} \times 100 \%$

$=\frac{5,481}{72,230} \times 100 \%$

$=7,589 \%$

7. Tip Speed Ratio (TSR)

$\mathrm{TSR}=\frac{\pi x D x n}{60 x v}$

$$
\begin{aligned}
& =\frac{\pi x 0.88 \times 227.7}{606} \\
& =1.748
\end{aligned}
$$

Berikut ini adalah grafik hasil perhitungan yang telah dilakukan seperti pada contoh diatas.

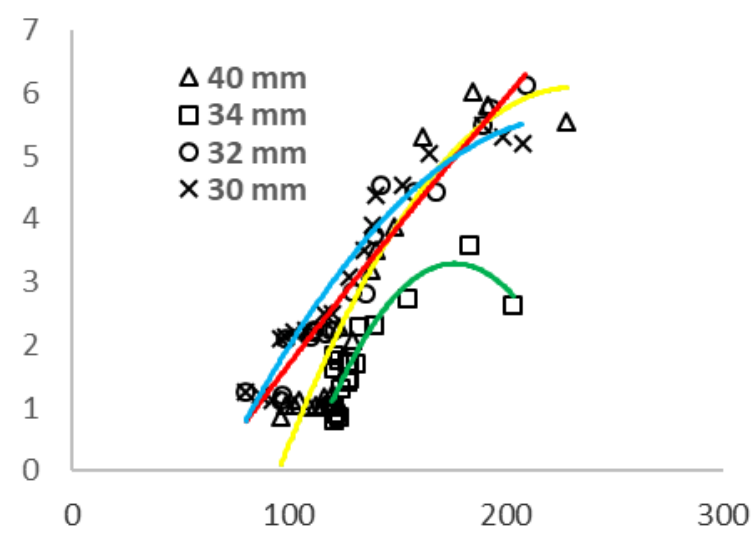

Gambar 2. Grafik Hubungan Efisiensi Sistem terhadap Putaran pada Lebar Sudu $80 \mathrm{~mm}$ dengan kecepatan angin $6 \mathrm{~m} / \mathrm{s}$

Gambar 2 merupakan grafik hubungan efisiensi sistem terhadap putaran pada lebar sudu $80 \mathrm{~mm}$ dengan kecepatan angin $6 \mathrm{~m} / \mathrm{s}$ pada variasi lebar celah masuk air exit $40 \mathrm{~mm}, 34 \mathrm{~mm}, 32 \mathrm{~mm}$ dan $30 \mathrm{~mm}$. Grafik di atas menunjukkan bahwa terdapat perbedaan trendline pada variasi lebar celah masuk air exit $40 \mathrm{~mm}, 34 \mathrm{~mm}, 32 \mathrm{~mm}$ dan $30 \mathrm{~mm}$. Berdasarkan grafik diatas menunjukkan bahwa apabila semakin bertambahnya lebar celah masuk air exit maka putaran turbin akan semakin bertambah. trendline pada grafik diatas membentuk 
kurva hiperbolik dan terdapat bentuk yang sedikit lurus. Efisiensi sistem tertinggi yang dihasilkan pada grafik diatas yaitu pada lebar celah masuk air exit $32 \mathrm{~mm}$ dengan efisiensi sistem yang dihasilkan sebesar $6.117 \%$ pada putaran generator $104.45 \mathrm{rpm}$

Gambar 3 merupakan grafik hubungan efisiensi sistem terhadap putaran pada lebar sudu $80 \mathrm{~mm}$ dengan kecepatan angin $7 \mathrm{~m} / \mathrm{s}$ pada variasi lebar celah masuk air exit $40 \mathrm{~mm}, 34 \mathrm{~mm}, 32$ $\mathrm{mm}$ dan $30 \mathrm{~mm}$. Grafik di atas menunjukkan bahwa terdapat perbedaan trendline pada variasi lebar celah masuk air exit $40 \mathrm{~mm}, 34 \mathrm{~mm}, 32 \mathrm{~mm}$ dan 30 mm. Berdasarkan grafik diatas menunjukkan bahwa apabila semakin bertambahnya lebar celah masuk air exit maka putaran turbin akan semakin bertambah. trendline pada seluruh grafik diatas membentuk kurva hiperbolik dan terdapat bentuk yang sedikit lurus. Efisiensi sistem tertinggi yang dihasilkan pada grafik diatas yaitu pada bukaan celah $30 \mathrm{~mm}$ dengan efisiensi sistem yang dihasilkan sebesar $4.3 \%$ pada putaran generator 103.40 rpm. Putaran pada Lebar Sudu $80 \mathrm{~mm}$ dengan kecepatan angin $8 \mathrm{~m} / \mathrm{s}$

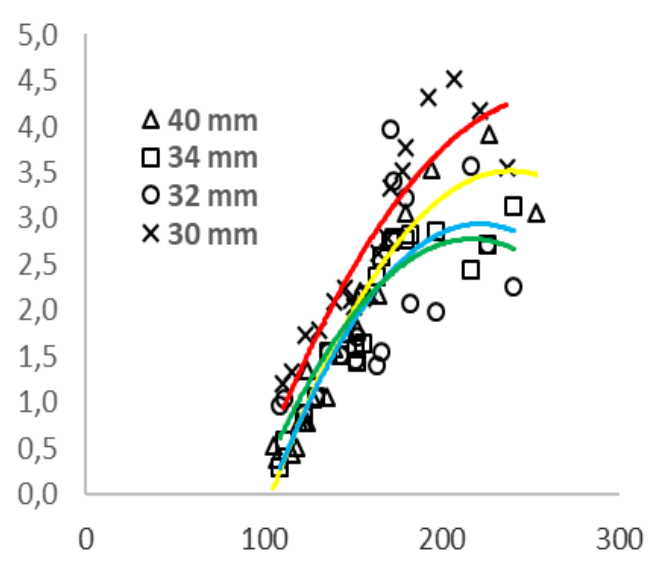

Gambar 4. Grafik Hubungan Efisiensi Sistem terhadap Putaran pada lebar sudu 80 kecepatan angina $8 \mathrm{~m} / \mathrm{s}$

Gambar 4 diatas merupakan grafik hubungan defisiensi sistem terhadap putaran pada lebar sudu $80 \mathrm{~mm}$ dengan kecepatan angin $8 \mathrm{~m} / \mathrm{s}$ pada variasi lebar celah masuk air exit $40 \mathrm{~mm}, 34 \mathrm{~mm}, 32$ $\mathrm{mm}$ dan $30 \mathrm{~mm}$. Gambar 3. di atas menunjukkan bahwa terdapat perbedaan trendline pada variasi lebar celah masuk air exit $40 \mathrm{~mm}, 34 \mathrm{~mm}, 32 \mathrm{~mm}$ dan 30 $\mathrm{mm}$. Gambar 4 diatas menunjukkan bahwa apabila semakin bertambahnya lebar celah masuk air exit maka putaran turbin akan semakin bertambah. trendline pada seluruh grafik diatas membentuk kurva hiperbolik. Efisiensi sistem tertinggi yang dihasilkan pada grafik diatas yaitu pada lebar celah masuk air exit $30 \mathrm{~mm}$ dengan efisiensi sistem yang dihasilkan sebesar 2,91\% pada putaran generator $274,49 \mathrm{rpm}$.

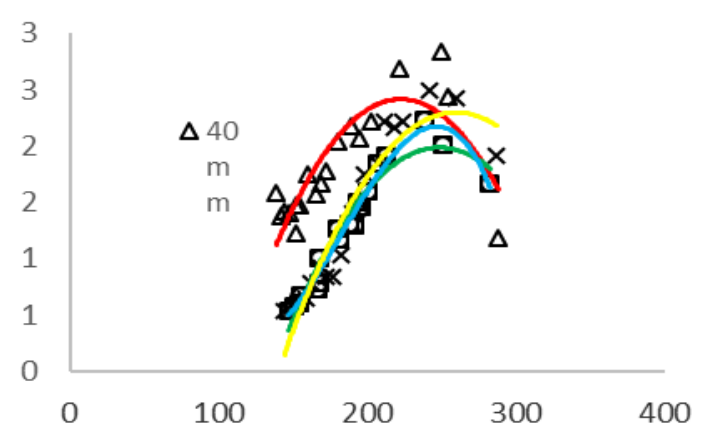

Gambar 5. Grafik Hubungan Efisiensi Sistem terhadap Putaran pada Lebar Sudu $80 \mathrm{~mm}$ dengan kecepatan angin $9 \mathrm{~m} / \mathrm{s}$

Gambar 5 diatas merupakan hubungan efisiensi sistem terhadap putaran pada lebar sudu $80 \mathrm{~mm}$ dengan kecepatan angin $9 \mathrm{~m} / \mathrm{s}$ pada variasi lebar celah masuk air exit $40 \mathrm{~mm}, 34 \mathrm{~mm}, 32$ $\mathrm{mm}$ dan 30 mm.Grafik di atas menunjukkan bahwa terdapat perbedaan trendline pada variasi lebar celah masuk air exit $40 \mathrm{~mm}, 34 \mathrm{~mm}, 32 \mathrm{~mm}$ dan 30 mm. Gambar 5 diatas menunjukkan bahwa apabila semakin bertambahnya lebar celah masuk air exit maka putaran turbin akan semakin bertambah. trendline pada seluruh grafik diatas membentuk kurva hiperbolik. Efisiensi sistem tertinggi yang dihasilkan pada grafik diatas yaitu pada bukaan celah air exit $40 \mathrm{~mm}$ dengan efisiensi sistem yang 
dihasilkan sebesar $2.834 \%$ pada putaran generator 222,3rpm.

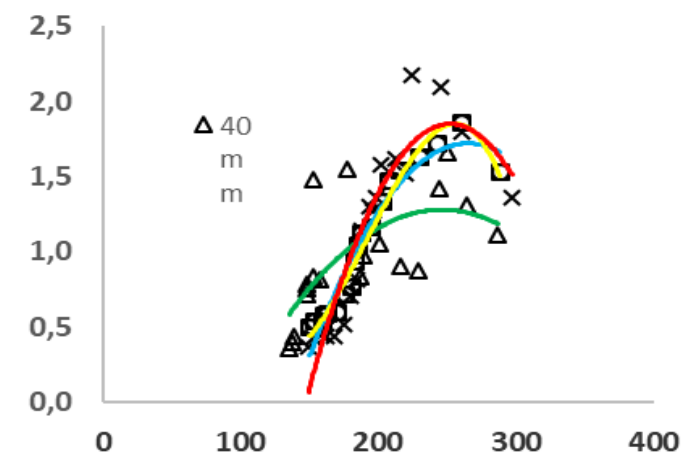

Gambar 6. Grafik Hubungan Efisiensi Sistem terhadap Putaran pada Lebar Sudu $80 \mathrm{~mm}$ dengan kecepatan angin $10 \mathrm{~m} / \mathrm{s}$

Gambar 6 merupakan grafik hubungan efisiensi sistem terhadap putaran pada lebar sudu $80 \mathrm{~mm}$ dengan kecepatan angin $10 \mathrm{~m} / \mathrm{s}$ pada variasi lebar celah masuk air exit $40 \mathrm{~mm}, 34 \mathrm{~mm}, 32 \mathrm{~mm}$ dan $30 \mathrm{~mm}$.Grafik di atas menunjukkan bahwa terdapat perbedaan trendline pada variasi lebar celah masuk air exit 40 $\mathrm{mm}, 34 \mathrm{~mm}, 32 \mathrm{~mm}$ dan $30 \mathrm{~mm}$. grafik diatas menunjukkan bahwa apabila semakin bertambahnya lebar celah masuk air exit maka putaran turbin akan semakin bertambah. trendline pada seluruh grafik diatas membentuk kurva hiperbolik. Efisiensi sistem tertinggi yang dihasilkan pada grafik diatas yaitu pada lebar celah masuk air exit $30 \mathrm{~mm}$ dengan efisiensi sistem yang dihasilkan sebesar $1,86 \% \%$ pada putaran generator 252,68 rpm.

\section{Kesimpulan}

Berdasarkan data pengujian dan analisis, maka dapat diambil kesimpulan efisiensi terbaik pada sudu flat lebar sudu $80 \mathrm{~mm}$ yaitu sebesar $6,01 \%$ untuk putaran 184,2 rpm pada kecepatan angin $6 \mathrm{~m} / \mathrm{s}$ dengan penambahan air exit variasi lebar celah masuk $40 \mathrm{~mm}$. Efisiensi terbaik pada sudu flat lebar sudu $100 \mathrm{~mm}$ yaitu sebesar 3,29\% untuk putara $176,3 \mathrm{rpm}$ pada kecepatan angin $6 \mathrm{~m} / \mathrm{s}$ dengan penambahan air exit variasi lebar celah masuk $40 \mathrm{~mm}$. Daya output terbaik pada sudu flat lebar sudu $100 \mathrm{~mm}$ yaitu sebesar 5,89 watt pada kecepatan angin $10 \mathrm{~m} / \mathrm{s}$ dengan penambahan air exit variasi lebar celah masuk $34 \mathrm{~mm}$ Turbin ini cocok untuk kecepatan angin rendah karena berdasarkan hasil pengujian efisiensi terbaik terjadi pada pengujian menggunakan kecepatan angin $6 \mathrm{~m} / \mathrm{s}$ dan $7 \mathrm{~m} / \mathrm{s}$ Semakin besar keepatan angin yang digunakan dalam pengujian daya output semakin besar namun efisiensinya semakin kecil. Penambahan air exit variasi lebar celah masuk $34 \mathrm{~mm}$

\section{Daftar Pustaka}

Ahlund, Karin. 2004. Investigation of the NREL NASAlAmes Wind Turbine Aerodynamics Database, Aeronautics FFASE-17290, Stockholm.

Andi, 2012. Turbin Angin Ripe Propeler.http://mit.ilearning.me/kincirangin-pembangkit-listrik. Himran, Syukri. 2005. Energi Angin. CVBintang. Makassar. 